\title{
Biomimetic sensors of molecularly-imprinted polymers for chlorpromazine determination
}

\author{
Felismina T.C. Moreira, M. Goreti F. Sales
}

A B S T R A C T

A new man-tailored biomimetic sensor for Chlorpromazine host-guest interactions and potentiometric transduction is presented. The artificial host was imprinted within methacrylic acid, 2-vinyl pyridine and 2-acrylamido-2-methyl-1-propanesulfonic acid based polymers. Molecularly imprinted particles were dispersed in 2-nitrophenyloctyl ether and entrapped in a poly(vinyl chloride) matrix. Slopes and detection limits ranged $51-67 \mathrm{mV} /$ decade and $0.46-3.9 \mu \mathrm{g} / \mathrm{mL}$, respectively, in steady state conditions. Sensors were independent from the $\mathrm{pH}$ of test solutions within 2.0-5.5. Good selectivity was observed towards oxytetracycline, doxytetracycline, ciprofloxacin, enrofloxacin, nalidixic acid, sulfadiazine, trimethoprim, glycine, hydroxylamine, cysteine and creatinine. Analytical features in flowing media were evaluated on a double-channel manifold, with a carrier solution of $5.0 \times 10^{-2} \mathrm{~mol} / \mathrm{L}$ phosphate buffer. Near-Nernstian response was observed over the concentration range $1.0 \times 10^{-4}$ to $1.0 \times 10^{-2} \mathrm{~mol} / \mathrm{L}$. Average slopes were about $48 \mathrm{mV} / \mathrm{decade}$. The sensors were successfully applied to field monitoring of CPZ in fish samples, offering the advantages of simplicity, accuracy, automation feasibility and applicability to complex samples.

Keywords:

Chlorpromazine

Molecularly-imprinted sensors

Potentiometry

FIA

Fish

\section{Introduction}

Industrial aquaculture is a rapidly growing industry in many developed and developing countries [1]. The introduction of veterinary medicines at the food production area has been the main responsible for this scenario. However, their wide use in aquaculture led to environmental and food spread of veterinary drugs [1,2]. Recognition of the risks has led to their limited or prohibited use in aquaculture production [3].

CPZ is a phenothiazine drug with an aliphatic side chain (Fig. 1), used in the management of psychotic conditions [4]. It controls excitement, agitation and other psychomotor disturbances, controlling hyperkinetic states and aggression. CPZ was used for veterinary purposes as an antiemetic, pre-anesthetic and muscle relaxant. Its use in food-producing animals is today banned from EU (according to the Council's regulation 2377/90) because no safe level of residue can be determined.

Many methods have been reported to determine phenothiazines, including CPZ. Most of them imply optical-based methods, namely spectrophotometric [5-17], fluorimetric [18-22], and turbidimetric [23] procedures that regard several chemical transformations of CPZ. High Performance Liquid Chromatography (HPLC) [24-33] electrophoresis [34] voltammetric [11,35-37], coloumetric [38], polarographic [39] and spectroelectrochemical [12] procedures have been reported as well.
Overall, these methods involve several time-consuming manipulation steps and/or require sophisticated equipment, being also a source of wastewaters of considerable high toxicity. Alternative and advantageous methods should rely on expeditious and efficient procedures providing highly specific and sensitive measurements.

Chemical sensors of potentiometric transduction could fulfill these requirements. Ion-selective electrodes (ISEs) offer high precision and rapidity, low cost of analysis, and enhanced selectivity and sensitivity over a wide range of concentrations [40,41]. For membrane-based devices the selectivity and sensitivity is mainly governed by the ionophore or the ion carrier [42]. Ion exchangers and neutral macrocyclic compounds have been employed over the past decades for this purpose. To our knowledge, the only two CPZ selective electrodes reported in literature $[43,44]$ employed ion-exchangers as sensing materials.

The design of sensing materials that are complementary to the size and charge of a particular ion can lead however to an increased selectivity of the sensing unit. For this purpose, molecularly imprinted polymers (MIPs) can be easily tailored with suitable selectivity for a guest molecule [45-47]. The preparation of MIPs involves the polymerization of functional monomers in the presence of template molecules and initiators. After polymerization, the template molecules are removed, leaving accessible binding sites that maintain the ordered arrangement of complimentary chemical functionalities of the template and the overall spatial configuration of the target molecule.

Although there are various MIP applications, including chromatography [48-50] artificial antibodies [51-53] chemical sensors [54-56], 
<smiles>C=Cc1ccccn1</smiles>

AAMPSO<smiles>C=C(C)C(=O)OCC(CC)(COC(=O)C(=C)C)OC(=O)C(=C)C</smiles><smiles>C=CC(=O)NC(C)(C)CS(=O)(=O)O</smiles><smiles>C=C(C)C(=O)OCCOC(=O)C(=C)C</smiles>

Fig. 1. Chemical structures of MIP reagents.

and solid-phase extraction (SPE) [57-59], until now, only few works in literature report the use of MIP as potentiometric PVC membrane sensing materials [60-63]. However, MIPs should play an advantageous role when associated to potentiometric sensors. Ion-selective electrodes (ISEs) use membranes to enable the selective recognition of a specific ion by transferring it (selectively) across the interface between the sample and membrane phase. This transfer generates a potential difference that is a measure of the activity of the transferred ion. Until now, several mechanisms have been suggested for this purpose. One of these is based on a selective complexation between the target ion and a "specific carrier" included in the membrane. A specific carrier binds a target analyte selectively.

MIPs acting as a carrier provide a means to enhance the selectivity of ISEs membranes. These materials are designed to carry out specific host-guest interactions between template and carrier. Once the imprinted templates are washed out from the polymeric matrix, they leave behind binding sites with specific shape and functional group complementarily in the polymeric network. These sites have the ability to rebind the analyte, generating an emf variation.

Therefore, the present work reports the development of CPZ MIPbased ISEs. The polymeric sensor was synthesized with methacrylic acid (MAA), 2-vinyl pyridine (VP) or 2-acrylamido-2-methyl-1propanesulfonic acid (AAMPSO) functional monomers, cross-linked by ethylene glycol dimethacrylic acid (EGDMA) or trimethylolpropane trimethacrylate (TRIM) within the template molecule (see chemical structures in Fig. 1). The sensing materials are dispersed in PVC plasticized with 0 -nitrophenyl octyl ether (oNPOE). The sensors are evaluated in steady-state and flowing media, and applied to the analysis of fish samples.

\section{Experimental}

\subsection{Apparatus}

All potential measurements were made in a Crison $\mu \mathrm{pH} 2002$ decimilivoltammeter $( \pm 0.1 \mathrm{mV}$ sensitivity), at room temperature, and under constant stirring by means of a Crison micro ST 2038. The output signal in steady state evaluations was transferred to a commutation unit and reconnected to one of six ways out, enabling the simultaneous reading of six ISEs. The assembly of the potentiometric cell was as follows: conductive graphite | CPZ selective membrane | buffered sample solution (phosphate, $5 \times 10^{-2} \mathrm{~mol} / \mathrm{L}, \mathrm{pH} 4.5$ ) || electrolyte solution, $\mathrm{KCl}|\mathrm{AgCl}(\mathrm{s})| \mathrm{Ag}$. The reference electrode was an Orion $\mathrm{Ag} / \mathrm{AgCl}$ double-junction (Orion 90-02-00). The selective electrode was prepared in conventional or tubular configurations [64] for batch and flow mode evaluations, respectively. Both devices had no internal reference solution and epoxy-graphite was used as solid contact.

The FIA assembly had a Gilson Minipuls 2 peristaltic pump, fitted with PVC tubing $(0.80,1.60$ and/or $2.00 \mathrm{~mm}$ i.d.), and a four-way Rheodyne 5020 injection valve holding a loop of variable volume. The several components were joined by PTFE tubing (Omnifit, Teflon, $0.8 \mathrm{~mm}$ i.d.), Gilson end-fittings and connectors. The support devices for tubular and reference electrodes, and the confluence point accessory were constructed in Perspex [64]. After reaching a stable baseline, the emf was recorded continuously by means of a homemade high-impedance data acquisition eight-channel box connected to a PC through the interface ADC 16 (Pico Tech., UK) and PicoLog for windows (version 5.07) software.

The $\mathrm{pH}$ was measured by a Crison CWL/S7 combined glass electrode connected to a decimilivoltammeter Crison, pH meter, GLP 22.

\subsection{Reagents}

All chemicals were of analytical grade and de-ionized water (conductivity $<0.1 \mu \mathrm{S} / \mathrm{cm}$ ) was employed. CPZ, potassium tetrakis(4chlorophenyl)borate (TpClPB), o-nitrophenyloctyl ether (oNPOE), poly (vinyl chloride) (PVC) of high molecular weight, EGDMA, VP, AAMPSO, MAA, acetonitrile (AcN) and ethanol were purchased from Fluka. Benzoyl peroxide (BPO), methanol (MeOH) and tetrahydrofuran (THF) were obtained from Riedel-deHäen and TRIM from Aldrich.

\subsection{Synthesis of host-tailored polymers}

MIPs were synthesized by placing the template (CPZ, $0.25 \mathrm{mmol})$ in a glass tube $(14 \mathrm{~mm}$ i.d) with the functional monomer (MAA, AAMPSO or VPY, $2.0 \mathrm{mmol}$ ), the cross-linker (EGDMA or TRIM, $10.0 \mathrm{mmol}$ ) and the radical initiator (BPO, $0.50 \mathrm{mmol}$ ), all dissolved in $3 \mathrm{~mL}$ of porogenic solvent ( $\mathrm{MeOH}, \mathrm{EtOH}, \mathrm{AcN}$ or THF). The mixture was sonicated, degassed with nitrogen for $5 \mathrm{~min}$, and cured at $70^{\circ} \mathrm{C}$ for $30 \mathrm{~min}$. Non-imprinted polymers (NIP) was prepared similarly by excluding the template from the procedure.

The resulting polymers were ground and sieved to particle sizes ranging from 50 to $150 \mu \mathrm{m}$. Extraction of the template molecule and washout of non-reacted species was carried out with $\mathrm{MeOH}$ / acetic acid (5:1, v/v). The absence of template on MIP particles was confirmed by measuring the absorbance of the washout solution at $255 \mathrm{~nm}$. All polymers were dried at $60^{\circ} \mathrm{C}$ until constant weight before use.

\subsection{Preparation of the potentiometric sensor}

The sensing membranes were prepared by mixing $200 \mathrm{mg}$ of PVC, $400 \mathrm{mg}$ of oNPOE and $7 \mathrm{mg}$ of MIP or NIP (Table 1). Some membranes were added of $2 \mathrm{mg}$ of TpCIPB acting as anionic additive. The mixture was stirred until the PVC was well moistened and dispersed in $3.0 \mathrm{~mL}$

Table 1

Binding parameters of MIP polymers.

\begin{tabular}{|c|c|c|c|c|c|c|}
\hline \multirow[t]{2}{*}{ Monomer } & \multirow[t]{2}{*}{ Solvent } & \multirow{2}{*}{$\begin{array}{l}\text { Cross } \\
\text { linker }\end{array}$} & \multicolumn{2}{|c|}{ High affinity binding site } & \multicolumn{2}{|c|}{ Low affinity binding site } \\
\hline & & & $\begin{array}{l}\mathrm{K}_{d} \\
(\mu \mathrm{mol} / \mathrm{L})\end{array}$ & $\begin{array}{l}\mathrm{Q}_{\max } \\
(\mu \mathrm{mol} / \mathrm{g})\end{array}$ & $\begin{array}{l}\mathrm{K}_{d} \\
(\mu \mathrm{mol} / \mathrm{L})\end{array}$ & $\begin{array}{l}\mathrm{Q}_{\max } \\
(\mu \mathrm{mol} / \mathrm{g})\end{array}$ \\
\hline MAA & $\mathrm{AcN}$ & TRIM & 404 & 288 & 3672 & 659 \\
\hline AAMPSO & $\mathrm{AcN}$ & TRIM & 1626 & 296 & 7042 & 562 \\
\hline VPY & $\mathrm{AcN}$ & TRIM & 338 & 806 & 2505 & 4544 \\
\hline MAA & THF & EDGMA & 578 & 86 & 5482 & 350 \\
\hline MAA & $\mathrm{MeOH}$ & EDGMA & 139 & 250 & 977 & 865 \\
\hline MAA & EtOH & EDGMA & 1452 & 1070 & - & - \\
\hline AAMPSO & $\mathrm{AcN}$ & EDGMA & 415 & 258 & - & - \\
\hline
\end{tabular}


THF. These membranes were placed in conductive supports of conventional or tubular shapes. Membranes were let dry for $24 \mathrm{~h}$. The electrodes were conditioned in a $1 \times 10^{-3} \mathrm{~mol} / \mathrm{L} \mathrm{CPZ}$ solution and kept in this solution when not in use.

\subsection{Potentiometric procedures}

All potentiometric measurements were carried out at room temperature. Emf values of each electrode were measured in solutions of fixed $\mathrm{pH}$ and ionic strength. Increasing concentration levels of CPZ were obtained by transferring $0.0200-10.0 \mathrm{~mL}$ aliquots of $1.0 \times$ $10^{-3} \mathrm{~mol} / \mathrm{L} \mathrm{CPZ}$ aqueous solutions to a $100 \mathrm{~mL}$ beaker containing $50.0 \mathrm{~mL}$ of $5.0 \times 10^{-2} \mathrm{~mol} / \mathrm{L}$ of suitable buffer. Potential readings were recorded after stabilization to $\pm 0.2 \mathrm{mV}$ and emf was plotted as a function of logarithm $\mathrm{CPZ}$ concentration. Calibration graphs were used for subsequent determination of unknown CPZ concentrations.

\subsection{Binding experiments}

Binding experiments were carried out by placing $20.0 \mathrm{mg}$ of MIP particles in contact with $10.0 \mathrm{~mL} \mathrm{CPZ} \mathrm{solutions} \mathrm{ranging} 0.08$ $10.0 \mathrm{mmol} / \mathrm{L}$. The mixtures were oscillated for $12 \mathrm{~h}$ at room temperature and the solid phase separated by centrifugation (3000 rpm, $10 \mathrm{~min}$ ). The concentration of free $\mathrm{CPZ}$ in the supernatant was detected by UV spectrophotometry at $255 \mathrm{~nm}$. The amount of CPZ bound to the polymer was calculated by subtracting the concentration of free $\mathrm{CPZ}$ from the initial CPZ concentration. The data obtained was used for Scatchard analysis.

\subsection{Determination of $\mathrm{CPZ}$ in fish}

Constant weights of well grinded fish $(\sim 2.0 \mathrm{mg})$ from aquaculture origin were transferred to $15 \mathrm{~mL}$ tubes. A $10 \mathrm{~mL}$ portion of $0.05 \mathrm{~mol} / \mathrm{L}$ phosphate buffer $\mathrm{pH} 4.5$ was added and thoroughly mixed with the fish sample. A sonication period of $5 \mathrm{~min}$ was allowed to ensured convenient extraction of the analyte. A supernatant liquid was obtained by centrifugation at $1000 \mathrm{rpm}$ and transferred into a $25 \mathrm{~mL}$ volumetric flask after filtration. Analytical measurements were conducted over this solution after completing the flask to final volume with buffer.

\section{Results and discussions}

The binding between the ionophore and the target ion is the molecular-level phenomenon, sensed by an ISE [42]. The binding strength between the selected ionophore and the analyte is the key to the selectivity of the potentiometric sensor. In a similar way, highly-specific imprinted polymers require the formation of stable complexes between templates and their functional monomers in the reaction mixture, as well as the preservation of these complexes in the resulting polymers. To that end, mostly covalent bonds have been used for fixation of the template molecules within the tailoredcavities. However, fast and reversible binding requires low activation energies. This is achieved by means of non-covalent binding, leading to sites that are less oriented than those in covalent imprinting but still with similar selectivity and sensitivity [65]. In this work, electrostatic interactions between CPZ and VP, AAMPSO or MAA monomers were considered to support the self-assembling of the sensor (that matches the shape of $\mathrm{CPZ}$ ). The contribution of monomer, cross-linker and solvent to host-guest binding properties were studied.

\subsection{Binding characteristic of MIP sensor}

Binding experiments were carried out by incubating fixed amounts of imprinted polymers with different concentrations of $\mathrm{CPZ}$ until equilibrium as reached. The resulting binding capacity of MIPs was calculated according to following equation:

$Q=\frac{\mu \operatorname{mol}(\text { CPZ bound })}{g(M I P)}=\frac{\left(C_{i}-C_{f}\right) V_{s} \times 1000}{M_{M I P}}$

where $\mathrm{Q}$ is binding capacity of MIPs ( $\mu \mathrm{mol} / \mathrm{g}$ ), $\mathrm{C}_{\mathrm{i}}$ the initial CPZ concentration $(\mu \mathrm{mol} / \mathrm{ml}), C_{\mathrm{f}}$ the final CPZ concentration $(\mu \mathrm{mol} / \mathrm{ml}), V_{\mathrm{s}}$ the volume of solution tested ( $\mathrm{ml}$ ), $\mathrm{M}_{\mathrm{MIP}}$ the mass of dried polymer ( $\mathrm{mg}$ ). Binding capacities were plotted against the initial CPZ concentration (Fig. 2A). The adsorption data showed that the binding capacity of imprinted polymer increased with the increasing of the initial concentration of $\mathrm{CPZ}$, reaching to saturation at higher concentrations.

The binding data were further processed with Scatchard analysis, providing important information on binding properties of the imprinted particles. The Scatchard equation,

$\mathrm{Q} / \mathrm{C}_{\text {free }}=\left(\mathrm{Q}_{\max }-\mathrm{Q}\right) / \mathrm{K}_{d}$

was applied for this purpose, where $\mathrm{Q}$ is the binding capacity; $C_{\text {free }}$ the free analytical concentration at equilibrium $(\mu \mathrm{mol} / \mathrm{L}) ; \mathrm{Q}_{\max }$ is the maximum apparent binding capacity; and $\mathrm{K}_{\mathrm{D}}$ is the dissociation constant at binding site. The equilibrium dissociation constant is calculated from the slopes and the apparent maximum number of binding sites from the $y$-intercepts in the linear plot of $\mathrm{Q} / \mathrm{C}_{\text {free }}$ versus $\mathrm{Q}$. The Scatchard plots in Fig. 2B showed either a linear behavior or a curve that could be understood as two straight lines. The former behavior suggests the existence of a single kind of binding site in MIPs while the later infers the existence of high and low affinity populations of binding sites.

The effect of monomer (Fig. 2A1 and B1) was studied for MAA, VPY and AAMPSO cross-linked with TRIM (see chemical structure in Fig. 1). In terms of acid/base properties, MAA and VPY play a similar role despite their different chemical functions, with pKa values of 4.7 and 5.0. AAMPSO had a quite smaller pKa $[-2.0,65]$ but combined in the same structure the sulfonic acid and the amide groups. Overall, all polymers have the ability to establish electrostatic interactions to CPZ. Adsorption plots evidenced higher binding capacities for VPY and smaller ones for AAMPSO based polymers. All MIPs showed heterogeneous binding sites. This heterogeneity was probably not correlated to the monomer under use, because every Scatchard analysis pointed out a similar behavior. VPY based MIPs displayed the smaller dissociation constant and with higher maximum apparent binding capacity (Table 1 ).

Adsorption experiments of MIPs of MAA/EDGMA prepared with different porogenic solvents displayed similar behavior when $\mathrm{MeOH}$ or EtOH were used (Fig. 2A2). The use of THF originated smaller binding capacities, showing a tendency for saturation at lower CPZ concentrations. With regard to binding places, only polymers produced with EtOH showed a Scatchard plot with a single straight line (Fig. 2B2), however, the dissociation constant for this MIP was very high. Overall, $\mathrm{MeOH}$ improved the binding parameters of the MIP particles for producing small $\mathrm{K}_{d}$ and high $\mathrm{Q}_{\max }$ values.

In general, the observed binding capacities for EDGMA cross-linker are much higher than those using TRIM (Fig. 2A). Their chemical structures are shown in Fig. 1. EDGMA seemed to be associated to the existence of a single kind of binding site for interaction to the template molecule, because only polymers using this cross-linker displayed a linear Scatchard plot.

From the above results, it seemed clear that the use of $\mathrm{MeOH}$ associated to EDGMA cross-linker could improve the binding properties of CPZ MIPs. Therefore, potentiometric sensors were prepared with these reagents and using MAA, AAMPSO or VPY as monomer. 

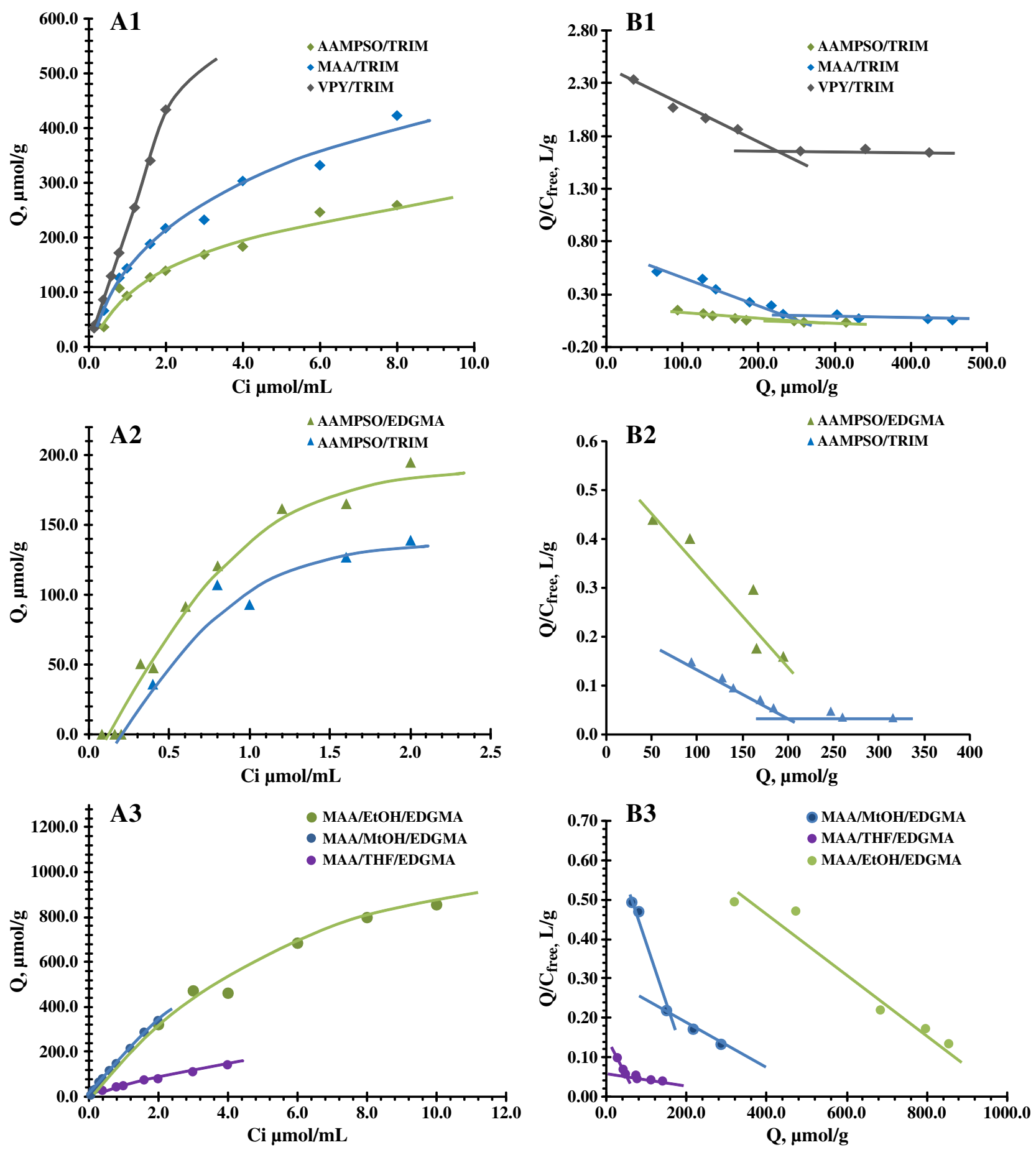

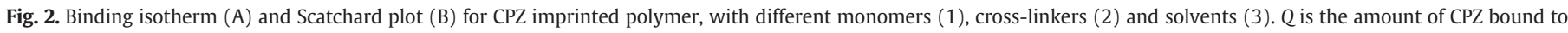
$20.0 \mathrm{mg}$ of the respective polymer; $\mathrm{t}=25^{\circ} \mathrm{C} ; \mathrm{V}=10.0 \mathrm{~mL}$ and binding time: $20 \mathrm{~h}$.

\subsection{Selection of the electroactive material}

CPZ sensors contained MIP or NIP particles of MAA, VPY or AAMPSE as electroactive materials dispersed in oNPOE plasticizing solvent plus PVC. Their main analytical features were evaluated in steady state conditions and followed IUPAC recommendations [66]. The average results of four determinations are shown in Table 2.

In general terms, all sensors displayed near-Nerstnian behavior, with slopes ranging from 52.8 to $47.8 \mathrm{mV} /$ decade. MIP based sensors had, in general, more reproducible responses with lower limits of detection than NIP sensing devices. The quite similar behavior between NIP and MIP based sensors (see Fig. 1) suggest that electrostatic interactions between $\mathrm{CPZ}$ and the sensing system were being established with the corresponding functional groups and were mostly independent from their special arrangement.

\subsection{Effect of additive}

To improve the operating features of the previous membranes, the MIP-based sensors were added of an anionic lipophilic compound. Typically, the addition of an anionic compound of lipophilic nature to potentiometric sensors reduces the anionic interference and lowers 
Table 2

Membrane composition of PVC CPZ sensors and their average potentiometric features $(n=5)$ in $5.0 \times 10^{-2}$ mol/L phosphate buffer, $\mathrm{pH} 4.5$.

\begin{tabular}{|c|c|c|c|c|c|c|c|c|c|c|c|}
\hline \multirow[t]{2}{*}{ ISE } & \multicolumn{4}{|c|}{ Membrane composition } & \multirow{2}{*}{$\begin{array}{l}\text { Slope } \\
\text { (mV/decade) }\end{array}$} & \multirow[t]{2}{*}{ R squared } & \multirow{2}{*}{$\begin{array}{l}\text { LLLR } \\
(\mathrm{mol} / \mathrm{L})\end{array}$} & \multirow{2}{*}{$\begin{array}{l}\text { LOD } \\
(\mathrm{mol} / \mathrm{L})\end{array}$} & \multirow[t]{2}{*}{$\mathrm{pH}$ range } & \multirow{2}{*}{$\begin{array}{l}\sigma_{\mathrm{v}} \\
(\mathrm{mV})\end{array}$} & \multirow{2}{*}{$\begin{array}{l}\mathrm{Cv}_{\mathrm{w}} \\
(\%)\end{array}$} \\
\hline & Active ingredient & Plasticizer & Additive & Weight (mg) & & & & & & & \\
\hline I & MIP/MAA & $o N F O E$ & - & $15: 350$ & $51.4 \pm 2.8$ & 0.995 & $1.6 \times 10^{-5}$ & $1.1 \times 10^{-5}$ & $2-5.5$ & 1.6 & 0.5 \\
\hline II & NIP/MAA & $o N F O E$ & - & $15: 350$ & $52.8 \pm 2.1$ & 0.996 & $3.0 \times 10^{-5}$ & $2.2 \times 10^{-5}$ & $2-5.5$ & 2.9 & 1.5 \\
\hline III & MIP/VPY & oNFOE & - & $15: 350$ & $52.2 \pm 1.5$ & 0.996 & $3.0 \times 10^{-5}$ & $1.1 \times 10^{-5}$ & $2-5.5$ & 2.4 & 3.8 \\
\hline IV & NIP/VPY & oNFOE & - & $15: 350$ & $47.8 \pm 1.5$ & 0.996 & $3.0 \times 10^{-5}$ & $1.5 \times 10^{-5}$ & $2-5.5$ & 2.1 & 6.0 \\
\hline $\mathrm{V}$ & MIP/AAMPSO & oNFOE & - & $15: 350$ & $48.0 \pm 1.4$ & 0.996 & $3.0 \times 10^{-5}$ & $1.1 \times 10^{-5}$ & $2-5.5$ & 1.1 & 0.5 \\
\hline VI & NIP/AAMPSO & oNFOE & - & $15: 350$ & $49.0 \pm 3.1$ & 0.996 & $3.0 \times 10^{-5}$ & $1.4 \times 10^{-5}$ & $2-5.5$ & 0.3 & 1.2 \\
\hline VII & MIP/MAA & oNFOE & TpCIPB & $15: 350: 7$ & $54.6 \pm 1.2$ & 0.997 & $1.6 \times 10^{-5}$ & $1.3 \times 10^{-5}$ & $2-5.5$ & 0.9 & 1.2 \\
\hline VIII & MIP/VPY & oNFOE & TpCIPB & $15: 350: 7$ & $67.4 \pm 0.9$ & 0.995 & $1.6 \times 10^{-5}$ & $8.9 \times 10^{-6}$ & $2-5.5$ & 4.2 & 2.7 \\
\hline IX & MIP/AAMPSO & oNFOE & TpCIPB & $15: 350: 7$ & $55.7 \pm 3.9$ & 0.994 & $4.1 \times 10^{-6}$ & $1.3 \times 10^{-6}$ & $2-5.5$ & 0.3 & 0.1 \\
\hline
\end{tabular}

LLLR: Lower limit of linear range; LOD: Limit of detection; $\mathrm{Cv}_{\mathrm{w}}$ : coefficient variation in weekly calibration for $2.72 \times 10^{-4} \mathrm{~mol} / \mathrm{L}$.

the electrical resistance of the membranes [67]. In this work, TpClPB was selected as additive (Table 2). Sensors based in MIP/MAA, MIP/VP and MIP/AAMPSO showed linear response ranges after $1.6 \times 10^{-5}$, $1.6 \times 10^{-5}$ and $4.1 \times 10^{-6} \mathrm{~mol} / \mathrm{L}, 4.6,3.2$ and $0.46 \mu \mathrm{g} / \mathrm{mL}$ detection limits, and near-Nernstian responses of $54.6,67.4$ and $55.7 \mathrm{mV} /$ decade, respectively. When compared to the corresponding sensors without additive, a significant improvement in slope was observed for VP sensors and in lower limit of linear range for MAA sensors (see Fig. 3). AAMPSO base sensors displayed the wider concentration range of linear response.

\subsection{Effect of $p H$}

CPZ has three pKa values: 9.3, 9.4 and 8.1. Thus, its acid/base properties affect its protonation in aqueous media, thus conditioning the electrode response. This effect was investigated by following the variation in potential with change in $\mathrm{pH}$ by addition of very small amounts of concentrated hydrochloric acid or saturated sodium hydroxide solution. The emf of a standard solution of $5.0 \times 10^{-4} \mathrm{~mol} / \mathrm{L}$ $\mathrm{CPZ}$ was plotted against $\mathrm{pH}$ (Fig. 4).

The results indicated that the electrode did not respond to $\mathrm{pH}$ changes within 2.0 to 5.5 , range where emf variations were below \pm $10 \mathrm{mV}$. Generally, above pH 5.5 potentials started decreasing. This behavior was attributed to the formation of the free CPZ base in the solution, leading to a decrease in the concentration of chlorpromazinium ion. This was confirmed by a perceptible precipitation occurring at higher $\mathrm{pH}$ values.

NIP electrodes seemed more affected by $\mathrm{pH}$ because they drifted slightly along the acidic region while the others displayed an abrupt potential decay outside the operational $\mathrm{pH}$ range (Fig. 4).
Facing the wide operational $\mathrm{pH}$ range, a $\mathrm{pH}$ of 4.5 was selected because solubility and ionization of $\mathrm{CPZ}$ were favored in acidic medium.

\subsection{Sensor selectivity}

Selectivity of the chemical sensor is one of the most important potentiometric features regarding its analytical application. One component of the selective membrane that exerts great influence upon this property is the electroactive material, as the mechanism of selectivity is mainly governed by stereospecific and electrostatic aspects. The selectivity profile of each sensor was evaluated by means of potentiometric selectivity coefficients $\left(K_{\mathrm{CPZ}, \mathrm{J}}^{\mathrm{POT}}\right)$, assessed by the separate solution method (SSM) and mixed solution method (MSM) [66]. They indicated the degree of preferential interaction for CPZ over foreign species that are common in biological and food samples, such as other fluoroquinolones used in aquaculture, namely ciprofloxacin (CF), enrofloxacin (ENR) and nalidixic acid (Nalid), or other antibiotics namely oxytetracycline (Oxy) and doxytetracycline (Doxy), sulfadiazine (SDZ), and trimethoprim (TMP). Glycine (Gly), hydroxylamine (HDXL), cysteine (Cys) and creatinine $\left(\mathrm{Crea}^{+}\right)$were also included as possible interfering species.

The selectivity coefficients for SSM and MSM were plotted in Fig. 5 (expressed in $\log K_{\mathrm{CPZ}^{+}}^{\mathrm{POT}^{2+}}{ }^{2+}$ and calculated after the following equations:

$$
\begin{aligned}
& K_{C P Z, J}^{P O T}=a_{C P Z}^{\left(1-1 / Z_{J}\right)} e^{\left(E_{J}-E_{C P Z}\right) / S} \\
& K_{C P Z, J}^{P O T}=a_{C P Z} /\left(a_{J}\right)^{Z_{C Z Z} / Z_{J}}
\end{aligned}
$$
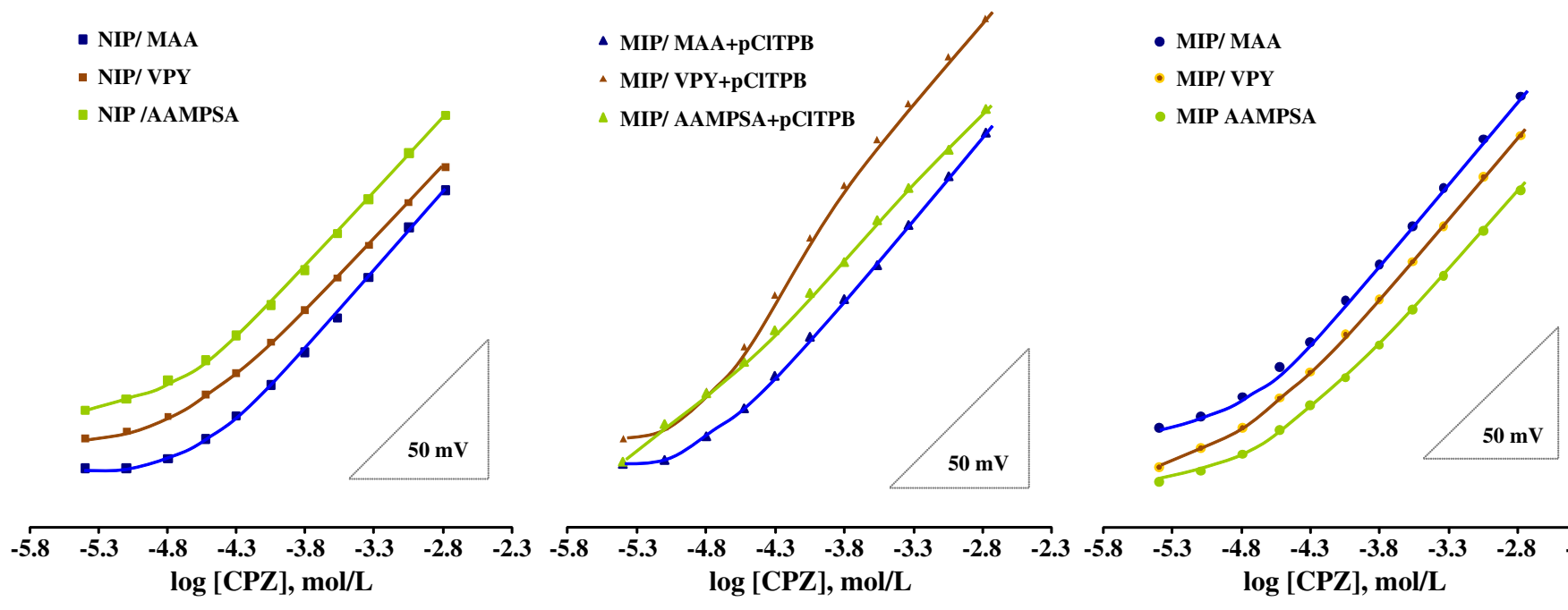

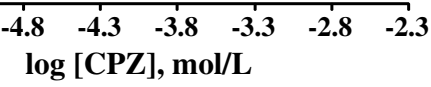

Fig. 3. Potentiometric response of NIP, MIP plus additive, and MIP sensors prepared with different monomers. 


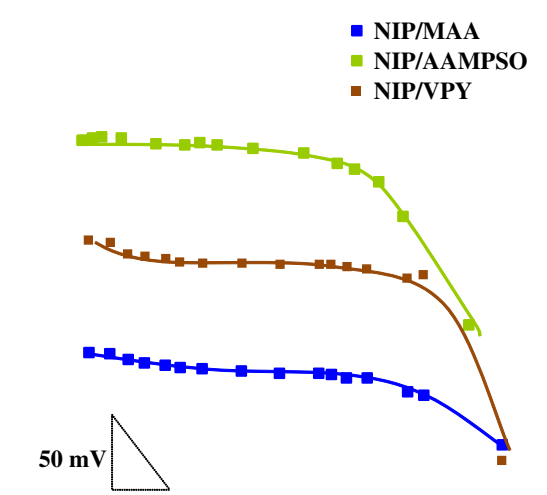

$\begin{array}{lllllllllll}0.0 & 1.0 & 2.0 & 3.0 & 4.0 & 5.0 & 6.0 & 7.0 & 8.0 & 9.0\end{array}$

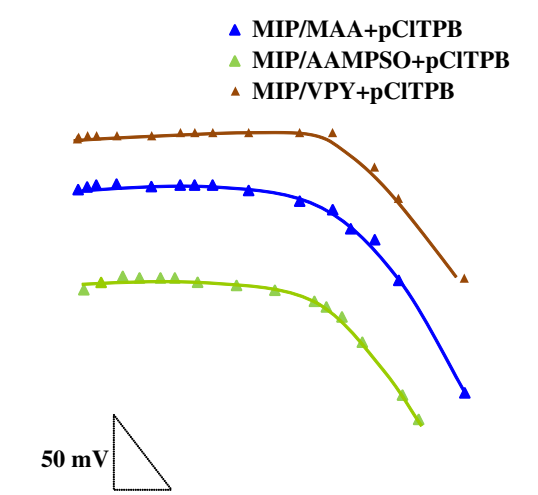

$\triangle$ MIP/MAA+pCITPB

$\triangle$ MIP/AAMPSO+pCITPB

MIP/VPY+pCITPB

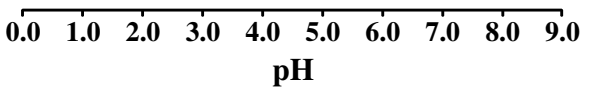

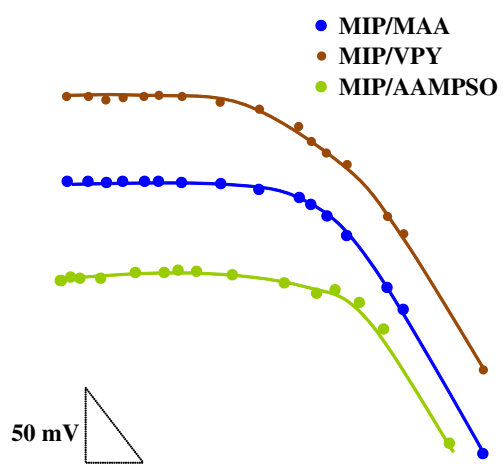

Fig. 4. Influence of the pH on the potential of NIP, MIP plus additive and MIP sensors prepared with different monomers.

In Eq. 3, $E_{C P Z}$ is the electrode potential in a $1.0 \times 10^{-3} \mathrm{~mol} / \mathrm{L} \mathrm{CPZ}$ solution, $E_{J}$ the potential of the electrode facing a $1.0 \times 10^{-3} \mathrm{~mol} / \mathrm{L}$ concentration in interfering species $J^{z+}$ of charge $Z$, and $S$ the practical slope calculated after the calibration experiments. In Eq. $4, a_{J}$ is $1.0 \times 10^{-3} \mathrm{~mol} / \mathrm{L}$ of interfering species, $Z$ the ionic charges of main and interfering ions and $a_{C P Z}$ the intersection of the extrapolated linear portions of the plot emf vs. the logarithm of CPZ concentration.

In general, MSM and SSM displayed quite different behaviors in terms of relative order of selectivity and the $\log K_{C P Z, J}^{P O T}$ absolute values of each interfering species, but all electrodes showed good selectivity for CPZ. Sensors with additive displayed higher $\log \mathrm{K}^{\mathrm{POT}}$ than the corresponding ones without additive, meaning that this membrane component decreased the selectivity of the electrodes. In terms of relative degree of selectivity, MAA and AAMPSO sensing devices showed a similar behavior, having better selectivity than VPY based sensors. The exception to this general behavior was observed for AAMPSO based electrodes evaluated by the SSM; the MIP particles provided the higher interference and the additive improved the selectivity of the sensing unit.

In general, interfering species were selected according to the intended application. If parent compounds, such as phenothyazine derivatives, are tested, the potentiometric response may be affected. This effect was not considered relevant because these compounds are not used concomitantly. Furthermore, if CPZ metabolic derivates are present, an alteration in the potentiometric response is also expected. In this case, this alterations favors the analytical screening of the drug,
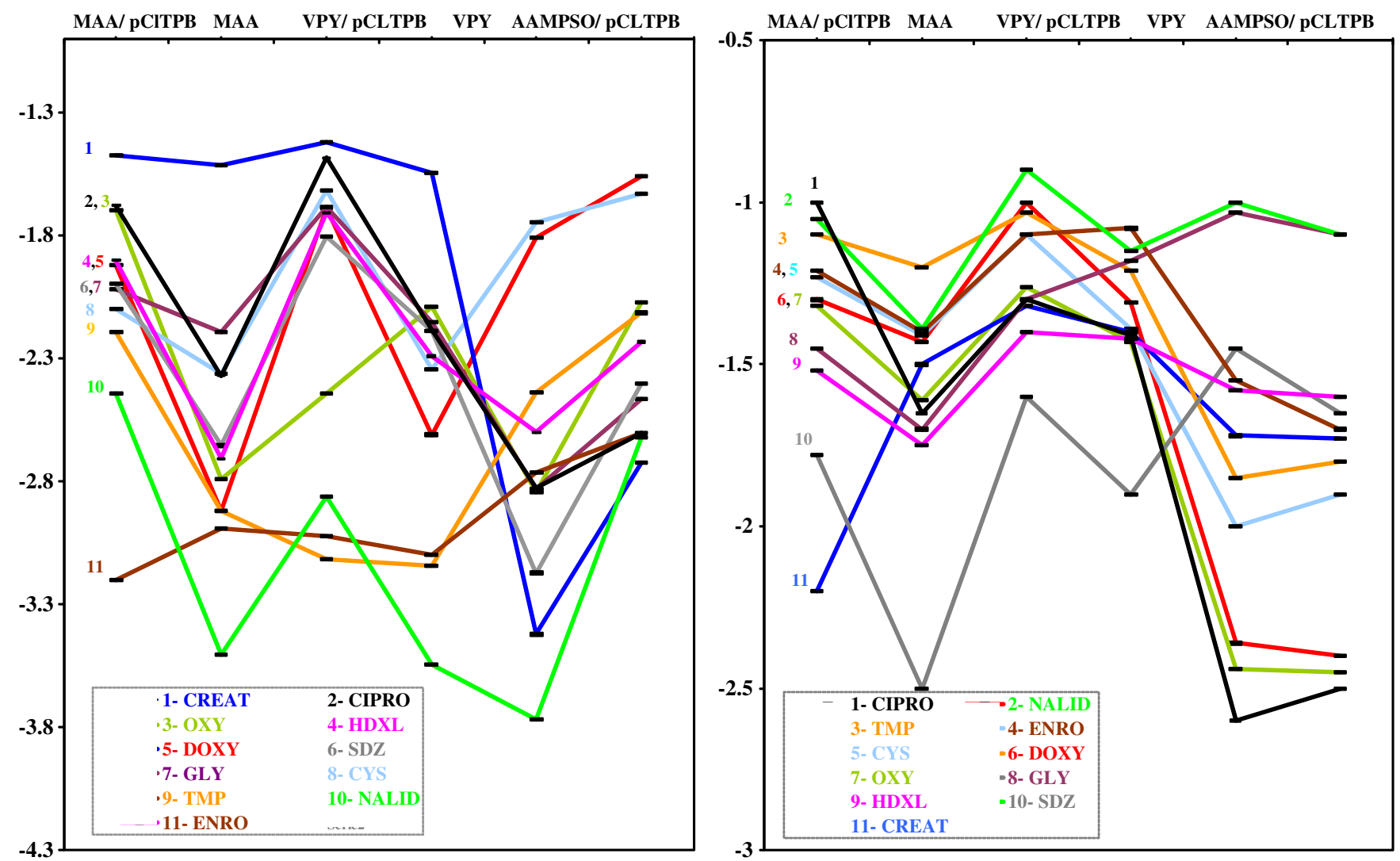

Fig. 5. Potentiometric selectivity coefficients (log $K^{\mathrm{POT}}$ ) with SSM (left) and MSM (right) of CPZ membrane based sensors, in 0.05 mol/L phosphate buffer of pH 4.5 . 
since it is correlated to its unwanted administration. Combining the selectivity behavior and the main analytical features of the electrodes, sensors of MIP/MAA were selected for further studies.

\subsection{Optimization of flow injection system}

For the routine control of an analyte, the continuous mode of operation is of regular selection. This may be achieved by means of flow injection analysis (FIA) systems. These are particularly attractive in view of their versatility, simplicity and suitability for large-scale analyses. The flow assembly was double-channel, allowing the on-line adjustment of $\mathrm{pH}$ and ionic strength. A flow cell of tubular configuration was used to accommodate the potentiometric device [64]. This cell was of simple fabrication, and allowed full membrane/sample contact, maintaining the general features of conventional configuration ISEs in terms of homogeneity, thickness and fixed area. The sensor of MIP/MAA with additive was used in this study for showing the best compromise between selectivity and sensitivity. To take full advantages of this FIA system, flow-rate and injection volume were optimized in terms of sensitivity, sampling-rate, reagent consumption and wastewater generation.

The sample loop was varied within 120 and $220 \mu \mathrm{L}$. For each injection volume, a set of CPZ standards ranging $1.0 \times 10^{-5}$ to $1.0 \times$ $10^{-3} \mathrm{~mol} / \mathrm{L}$ was injected into the buffer carrier stream. The dispersion decreased from 1.9 to 1.1 with increasing injection volumes. This observation was coupled to decreasing sampling rates because the sample plug took longer periods of time to cross the detector; for higher volumes the decay in sampling rate was not perceptible and the sample consumption increased by $83 \%$. Thus, as a compromise, the injection was set to $180 \mu \mathrm{L}$.

The flow rate was varied between 1.0 and $4.3 \mathrm{~mL} / \mathrm{min}$ for $\mathrm{CPZ}$ solutions ranging from $1.0 \times 10^{-5}$ to $1.0 \times 10^{-3} \mathrm{~mol} / \mathrm{L}$. No significant changes in slope were observed, but the peak width and peak height decreased with increasing flow-rates. As expected, experiments carried out at higher flow-rates presented higher sampling rates. Although this observation was coupled to a slight increase of the dispersion of sample solutions, this was not sufficient for a sensitivity decrease. For flow rates $\leq 2 \mathrm{~mL} / \mathrm{min}$ the tubular sensor required long time to recover to base line lowering the number of sample outputs. Therefore, a $4 \mathrm{~mL} / \mathrm{min}$ flow rate was chosen.

Under the previously selected conditions, the variation or fluctuation of the base line did not exceed $\pm 5 \%$ of the peak height. The MIP/MAA sensor displayed a $46.6 \mathrm{mV} /$ decade average slope, with detection limit of $7.0 \mu \mathrm{g} / \mathrm{mL}$ and lower limit of linear range of $1.0 \times$ $10^{-5} \mathrm{~mol} / \mathrm{L}$. The sampling-rate was approximately 35 runs per hour. The environmental effect of the emitted effluents was considered of small concern, containing mostly phosphate and CPZ. The total volume of effluent is also quite low, producing an average of $240 \mathrm{~mL}$ per hour.

\subsection{Monitoring CPZ in fish samples}

The method was applied to determine CPZ in fish samples that are typically produced in aquaculture, such as trout and seabass. Fish meat was grinded and spiked to $5-7 \mu \mathrm{g} / \mathrm{mL} \mathrm{CPZ}$. A good agreement was found between added and found amounts of CPZ (Table 3).

Table 3

Potentiomeric determination of CPZ in fish using MIP based membrane sensor.

\begin{tabular}{lcrc}
\hline Sample & $\mu \mathrm{g} \mathrm{CPZ/g}$ fish & Found $(\mathrm{mg})$ & Recovery $(\%)$ \\
\hline Fish 1 & 50 & $51.8 \pm 0.6$ & $103.7 \pm 1.3$ \\
& 100 & $103.5 \pm 2.2$ & $103.5 \pm 2.2$ \\
Fish 2 & 150 & $155.2 \pm 3.3$ & $103.5 \pm 2.2$ \\
& 50 & $51.7 \pm 2.4$ & $103.4 \pm 4.8$ \\
& 100 & $98.7 \pm 1.1$ & $98.7 \pm 1.1$ \\
& 150 & $148.1 \pm 2.2$ & $98.8 \pm 1.4$ \\
\hline
\end{tabular}

Results of the potentiometric analysis conducted in steady state showed recoveries ranging $99-104 \%$ with an average relative standard deviation of $2.2 \%$. The $t$-student and $\mathrm{F}$ tests confirmed that there were no significant differences between the means and variances of static and hydrodynamic potentiometric sets of results. The values of t-student and $\mathrm{F}$ tests were 2.63 and 1.04 , and 1.14 and 0.21 , respectively, for the two fish samples.

\section{Conclusions}

Molecular imprinting technique was employed to produce $\mathrm{CPZ}$ host-tailored sensors for potentiometric transduction. MAA, VPY and AAMPSO were used as monomers to produce different MIP materials. The effect of monomer, solvent and cross-linker were studied for this purpose.

All based sensors offered good potentiometric analytical features capable of discriminating other antibiotics in aqueous medium. Advantages of these sensors include the simplicity in designing, short measurement time, good precision, high accuracy, high analytical throughput, low limit of detection and good selectivity.

The MIP/MAA sensors were successfully applied to the analysis of food samples, both in steady state and in flowing media. The proposed method was simple, of low cost, precise, accurate and inexpensive regarding reagent consumption and equipment involved. Wastewaters discharged were of small concern to environment regarding its volume and composition.

The tubular devices were particularly suitable for the routine screening control of $\mathrm{CPZ}$ in fish meat. They produce quicker responses for $\mathrm{CPZ}$ than those provided by microbiological methods, and are much less expensive than the chromatographic methods that are used for routine purposes.

\section{Acknowledgments}

The authors acknowledge the financial support from FCT, Fundação para a Ciência e Tecnologia, by means of project PTDC/AGR-AAM/ 68359/2006.

\section{References}

[1] F.C. Cabello, Environ. Microbiol. 8 (2006) 1137-1144.

[2] T. Maki, I. Hirono, H. Kondo, T. Aoki, J. Fish Dis. 31 (2008) 461-468.

[3] Council Regulation (EEC) $2377 / 90$ of 26 June 1990 . Consolidated with previous amendments and published by 19 November 2005.

[4] T.J.R. Lambert, D.J. Castle, Accessed 6th Apr. 2009, at, http://www.mja.com.au/ public/issues/178_09_050503/lam10582_fm.pdf.

[5] Y.M. Huang, Z.H. Chen, Talanta 57 (2002) 953-959.

[6] S.M. Sultan, M.O.H. Al-Turabi, Talanta 51 (2000) 327-331.

[7] J. Karpinska, Anal. Lett. 33 (2000) 1555-1566.

[8] K. Tatsuya, K. Keisuke, T. Shigehiko, M. Yoko, N. Miwa, Chem. Pharm. Bull. 54 (2006) 972-976.

[9] K. Basavaiah, P. Nagegowda, H.C. Prameela, B.C. Somashekar, Indian J. Chem. Technol. 12 (2005) 25-29.

[10] T. Aman, J. Anwar, A. Ahmad, L. Latif, Anal. Lett. 36 (2003) 2961-2974.

[11] Y.N. Ni, I. Wang, S. Kokot, Anal. Chim. Acta 439 (2001) 159-168.

[12] D. Daniel, I.G.R. Gutz, J. Pharm. Biomed. Anal. 37 (2005) 281-286.

[13] M.D. Gowtham, M.S.Y. Kumar, M.A. Sathish, G. Nagendrappa, Arch. Pharm. 337 (2004) 605-614.

[14] K. Basavaiah, Indian J. Chem. Technol. 11 (2004) 632-638.

[15] D.B. Patil, D.M. Chafle, Asian J. Chem. 19 (2007) 3253-3255.

[16] H. Puzanowska-Tarasiewicz, L. Kuzmicka, J. Karpinska, K. Mielech-Lukasiewicz, Anal. Sci. 21 (2005) 1149-1153.

[17] K. Farhadi, M. Shamsipurb, Acta Chim. Slov. 50 (2003) 395-407.

[18] A. Quintana, Talanta 59 (2003) 417-422.

[19] F.A. Mohamed, H.A. Mohamed, S.A. Hussein, S.A. Ahmed, J. Pharm. Biomed. Anal. 39 (2005) 139-146.

[20] G.J. Yang, X.L. Qu, M. Shen, Q.S. Qu, C.Y. Wang, A.P. Zhu, X.Y. Hu, J. Fluoresc. 17 (2007) $119-126$.

[21] Y.H. Li, W.F. Niu, J.R. Lu, Talanta 71 (2007) 1124-1129.

[22] B.C. Xue, T. Wang, E.B. Liu, Spectrosc. Spect. Anal. 26 (2006) 816-820.

[23] K. Farhadi, A.K. Savojbolaghi, M. Farajzadeh, R. Maleki, Anal. Lett. 36 (2003) 2183-2198.

[24] M.A. Saracino, M. Amore, E. Baioni, C. Petio, M.A. Raggi, Anal. Chim. Acta 624 (2008) 308-316. 
[25] B. Zhang, J. Chromatogr. 854 (2007) 68-76.

[26] A. Maslanka, J. Krzek, J. AOAC Int. 88 (2005) 70-79.

[27] G. Zhang, A.V. Terry, M.G. Bartlett, J. Chromatogr. B 856 (2007) 20-28

[28] E. Tanaka, T. Nakamura, M. Terada, T. Shinozuka, C. Hashimoto, K. Kurihara, K. Honda, J. Chromatogr. B 854 (2007) 116-120.

[29] M. Cruz-Vera, R. Lucena, S. Cardenas, M. Valcarcel, J. Chromatogr. B 877 (2009) 37-42.

[30] H. Kirchherr, W.N. Kuhn-Velten, J. Chromatogr. B 843 (2006) 100-113.

[31] K. Madej, M. Kala, M. Wozniakiewicz, Chromatographia 62 (2005) 533-538.

[32] H.N. Choi, S.H. Cho, Y.J. Park, D.W. Lee, W.Y. Lee, Anal. Chim. Acta 541 (2005) 49-56.

[33] C. Pistos, J.T. Stewart, Biomed. Chromatogr. 17 (2003) 465-470.

[34] J.G. Li, F.J. Zhao, H.X. Ju, Anal. Chim. Acta 575 (2006) 57-61.

[35] M. Lukasiewicz, Anal. Lett. 41 (2008) 789-805.

[36] F.W.P. Ribeiro, A.S. Cardoso, R.R. Portela, J.E.S. Lima, S.A.S. Machado, P. De Lima, D. De Souza, A.N. Correia, Electroanalysis 20 (2008) 2031-2039.

[37] A. Ensafi, E. Heydari, Anal. Lett. 41 (2008) 2487-2502.

[38] D.B. Patil, D.M. Chafle, Asian J. Chem. 18 (2006) 497-502.

[39] F. Belal, S.M. El-Ashry, I.M. Shehata, M.A. El-Sherbeny, D.T. El-Sherbeny, Mikrochim. Acta 135 (2000) 147-154.

[40] V.V. Cosofret, R.P. Buck, Crit. Rev. Anal. Chem. 24 (1993) 1-58.

[41] S.K. Menon, A. Sathyapalan, Y.K. Agrawal, Rev. Anal. Chem. 16 (1997) 333-353.

[42] F. Faridbod, M.R. Ganjali, R. Dinarvand, P. Norouzi, Sensors 8 (2008) 2331-2412.

[43] M.G.F. Sales, J.F.C. Tomás, S.R. Lavandeira, J. Pharm. Biomed. Anal. 41 (2006) 1280-1286

[44] J.A. Ortuño, J. Hernández, C. Sánchez-Pedreño, Sensor. Actuat. B Chem. 119 (2006) 282-287.

[45] G. Wulff, Chem. Rev. 102 (2000) 1-27.

[46] G.J. Guan, B.H. Liu, Z.Y. Wang, Z.P. Zhang, Sensors 8 (2008) 8291-8320.

[47] E. Busi, R. Basosi, F. Ponticelli, M. Olivucci, J. Mol. Catal. Chem. 217 (2004) 31-36.

[48] K. Hosoya, Y. Shirasu, K. Kimata, N. Tanaka, Anal. Chem. 70 (1998) 943-945.
[49] B.J. Sellergren, Chromatogr. A 673 (1994) 133-141.

[50] P. Spegel, L. Schweitz, S. Nilsson, Electrophoresis 24 (2003) 3892-3899.

[51] N. Lavignac, C.J. Allender, K.R. Brain, Anal. Chim. Acta 510 (2004) 139-145.

[52] L. Ye, K. Mosbach, React. Funct. Polym. 48 (2001) 149-157.

[53] P. Manesiotis, A.J. Hall, J. Courtois, K. Irgum, B. Sellergren, Angew. Chem. Int. Ed. 44 (2005) 3902-3906.

[54] S. Marx, A. Zaltsman, A.I. Turyan, D. Mandler, Anal. Chem. 76 (2004) 120-126.

[55] M.C. Blanco-Lopez, M.J. Lobo-Castanon, A.J. Miranda-Ordieres, P. Tunon-Blanco, TRAC Trend Anal. Chem. 23 (2004) 36-48.

[56] O. Kriz, O. Ramstrom, K. Mosbach, Anal. Chem. 69 (1997) A345-A349.

[57] A.C.B. Dias, E.C. Figueiredo, V. Grassi, E.A.G. Zagatto, M.A.S. Arruda, Talanta 76 (2008) 988-996.

[58] F. Qiao, H. Sun, H. Yan, K.H. Row, Chromatographia 64 (2006) 625-634.

[59] M.M. Ariffin, E.I. Miller, P.A.G. Cormack, R.A. Anderson, Anal. Chem. 79 (2007) 256-262.

[60] A.H. Kamel, F.T.C. Moreira, S.A.A. Almeida, M.G.F. Sales, Electroanalysis 20 (2008) 194-202.

[61] K.P. Prathish, K. Prasad, T. Prasada-Raoa, M.V.S. Suryanarayana, Talanta 71 (2007) 1976-1980.

[62] G. D'Agostino, G. Alberti, R. Biesuz, M. Pesavento, Biosens. Bioelectron. 22 (2006) $145-152$.

[63] R.S. Hutchins, L.G. Bachas, Anal. Chem. 67 (1995) 1654-1660.

64] A.H. Kamel, S.A.A. Almeida, M.G.F. Sales, F.T.C. Moreira, Anal. Sci. 25 (2009) 365-371

[65] F.L. Dickert, O. Hayden, Trends Anal. Chem. 18 (1999) 192-199; 65 C. Klinke, A. Afzali, P. Avouris, Chem. Phys. Lett. 430 (2006) 75-79.

[66] Y. Umezawa, P. Bühlmann, K. Umezawa, K. Tohda, S. Amemiya, Pure Appl. Chem. 72 (2000) 1851-2082.

[67] M. Telting-Diaz, E. Bakker, Anal. Chem. 73 (2001) 5582-5589. 